\title{
Coronavirus disease 2019 (COVID-19): the portrait of a perfect storm
}

\author{
Giuseppe Lippi ${ }^{1}$, Fabian Sanchis-Gomar ${ }^{2,3}$, Brandon M. Henry ${ }^{4}$ \\ ${ }^{1}$ Section of Clinical Biochemistry, Department of Neuroscience, Biomedicine and Movement, University of Verona, Verona, Italy; ${ }^{2}$ Department of \\ Physiology, Faculty of Medicine, University of Valencia and INCLIVA Biomedical Research Institute, Valencia, Spain; ${ }^{3}$ Division of Cardiovascular \\ Medicine, Stanford University School of Medicine, Stanford, CA, USA; ${ }^{4}$ Cardiac Intensive Care Unit, The Heart Institute, Cincinnati Children's \\ Hospital Medical Center, OH, USA \\ Contributions: (I) Conception and design: G Lippi; (II) Administrative support: None; (III) Provision of study materials or patients: None; (IV) \\ Collection and assembly of data: All authors; (V) Data analysis and interpretation: All Authors; (VI) Manuscript writing: All authors; (VII) Final \\ approval of manuscript: All authors. \\ Correspondence to: Prof. Giuseppe Lippi. Section of Clinical Biochemistry, University Hospital of Verona, Piazzale LA Scuro, 37134 Verona, Italy. \\ Email: giuseppe.lippi@univr.it.
}

\begin{abstract}
The "novel" coronavirus disease 2019 (abbreviated "COVID-19") is the third coronavirus outbreak emerging during the past two decades. This infectious disease, sustained by Severe Acute Respiratory Syndrome Coronavirus 2 (SARS-CoV-2), has been recently declared a global pandemic by the World Health Organization. Despite the concerning epidemiological burden, many people, including some policymakers, are underestimating this pandemic and are remaining enigmatically inactive against a human pathology which, for a combination of reasons, can be reasonably defined as a perfect storm (i.e., the "wrong virus" at the "wrong time"). These many paradigmatic aspects include SARS-CoV-2 structure and peculiar biology of infection, high risk of inter-human transmission, long incubation time combined with early and sustained viral load, existence of asymptomatic or mildly-symptomatic carriers, viral shedding for days after symptom relief, unfavorable progression towards respiratory distress and death in up to $5-10 \%$ of patients thus causing dramatic healthcare challenges, as well as environmental contamination. Last but not least, the combination of the current case fatality rate with the extraordinary number of people that could be potentially infected by SARS-CoV-2 would permit to estimate that the worldwide deaths for COVID-19 may even approximate those recorded during World War II if appropriate restrictive measures for preventing human-to-human transmission are not readily undertaken. Everybody should be inexcusably aware that this is not a drill, and that the consequences of inadequate action will be tragedy.
\end{abstract}

Keywords: Outbreak; epidemics; coronavirus; coronavirus disease 2019 (COVID-19)

Submitted Mar 16, 2020. Accepted for publication Mar 30, 2020.

doi: 10.21037/atm.2020.03.157

View this article at: http://dx.doi.org/10.21037/atm.2020.03.157

\section{Introduction}

The "novel" coronavirus disease 2019 (abbreviated "COVID-19") is the third coronavirus outbreak to have emerged in the past twenty years, after Severe Acute Respiratory Syndrome (SARS) and Middle East Respiratory Syndrome (MERS) (1). This disease is caused by a member of the Coronaviridae family, which has been defined as
Severe Acute Respiratory Syndrome Coronavirus 2 (SARS$\mathrm{CoV}-2)$ by the International Committee on Taxonomy of Viruses (2).

Due to the incontrovertible evidence demonstrating worldwide diffusion of SARS-CoV-2, COVID-19 has recently been declared a global pandemic disease by the World Health Organization (WHO), when the General Director of the Agency, Tedros Adhanom Ghebreyesus, 
Table 1 Current epidemiology scenarios of influenza and coronaviruses outbreaks around the world and in some countries (Official World Health Organization data)

\begin{tabular}{|c|c|c|c|}
\hline Disease & Last update & Infected people/deaths & Death rate \\
\hline Influenza (Worldwide) ${ }^{\dagger}$ & December, 2019 & $1,387,882,608 / 319,213$ & $0.02 \%$ \\
\hline SARS (Worldwide) & April 21, 2004 & $8,096 / 774$ & $9.56 \%$ \\
\hline MERS (Worldwide) & November 25, 2019 & $2,494 / 858$ & $34.40 \%$ \\
\hline COVID-19 (Worldwide) & March 15, 2020 & $153,517 / 5,735$ & $3.74 \%$ \\
\hline - Australia & & $249 / 3$ & $1.20 \%$ \\
\hline - China & & $81,048 / 3,204$ & $3.95 \%$ \\
\hline - France & & $4,469 / 91$ & $2.04 \%$ \\
\hline - Germany & & $3,795 / 8$ & $0.21 \%$ \\
\hline - Iran & & $12,729 / 608$ & $4.78 \%$ \\
\hline - Russian Federation & & $34 / 0$ & - \\
\hline - Spain & & $5,753 / 136$ & $2.37 \%$ \\
\hline - Republic of Korea & & $8,162 / 75$ & $0.92 \%$ \\
\hline - United Kingdom & & $1,144 / 21$ & $1.84 \%$ \\
\hline - United States of America & & $1,678 / 41$ & $2.44 \%$ \\
\hline
\end{tabular}

${ }^{\dagger}$, seasonal data. COVID-19, coronavirus disease 2019; MERS; Middle East Respiratory Syndrome; SARS, Severe Acute Respiratory Syndrome.

warned the entire world on "the alarming levels of spread and severity, and by the alarming levels of inaction" (3). The epidemiologic burden of COVID-19 is constantly evolving, with numbers of infected persons, hospital admissions and deaths growing near exponentially. The last Situation Report of the WHO attests that COVID-19 has already infected as many as 153,517 people up to March 15, 2020, from 144 countries, causing 5,735 deaths (4).

Based on the information garnered to-date on COVID-19, the outbreak caused by SARS-CoV-2 could be reasonably defined as a kind of perfect storm (i.e., the "wrong virus" at the "wrong time"), for a combination of reasons. These include SARS-CoV-2 structure and peculiar biology of infection, high risk of inter-human transmission, long incubation time combined with early and sustained virus load, existence of asymptomatic or mildly-symptomatic carriers, viral shedding for days after symptom relief, and unfavorable progression towards respiratory distress and death in up to $5-10 \%$ of cases. For these reasons, COVID-19 will cause dramatic healthcare challenges and environmental contamination. Last but not least, although the most recent WHO statistics would presume us to conclude that the death rate of COVID-19 is still not as high as that of SARS or MERS, the extraordinary number of people that can be infected by SARS-CoV-2 compared to both former coronaviruses outbreaks sustained by SARS-CoV and MERS-CoV, would make COVID-19 the most deadly of such infections. In effect, the overall mortality rate is now about $3.7 \%$, displaying magnified peaks in certain countries like Italy $(6.81 \%)$ and Iran $(4.78 \%)$ (Table 1). For a purposeful comparison, the WHO has estimated that influenza causes between 250,000-500,000 deaths globally each year (5). Thus, it can be estimated that the mortality rate of influenza is $\sim 0.023 \%$, accounting for nearly 319,213 deaths in 1.39 billion people infected by this virus annually. Taking for granted the current $~ 3.7 \%$ death rate for COVID-19, and hypothesizing a similar number of people infected as for influenza, this would theoretically translate into as many as 52 million deaths worldwide for COVID-19, a number that is not so far from the approximately 75 million casualties recorded during World War II. 
Table 2 Peculiar characteristics of coronavirus disease 2019 (COVID-19)

- Viral structure and biology of infection

- High risk of inter-human transmission

- Long incubation time combined with early and sustained virus load

- Existence of asymptomatic or mildly-symptomatic carriers

- Unfavorable progression causing healthcare challenges

- Environmental contamination

- Viral shedding after symptom relief

Despite this concerning epidemiological burden, we share the impression that many people around the world, including some policymakers, are underestimating the seriousness of this pandemic, and are remaining enigmatically inactive, as also emphasized by Ghebreyesus (3). For this reason, in the following sections of this article, we will discuss the available scientific evidence supporting the need for urgent restrictive measures to contain this pandemic (Table 2). If not, it will likely progress to even more deaths than a third worldwide large-scale military conflict.

\section{Viral structure and biology of the infection}

From phylogenic evidence, it can now be reasonably concluded that SARS-CoV-2 most likely derives from a bat coronavirus, after undergoing some level of recombination that boosted its virulence in humans (6). SARS-CoV-2 penetrates the host cell through interaction between its spike (S) glycoprotein and a plasma membrane protein, the angiotensin-converting enzyme 2 (ACE2) receptor, which is present in a vast array of cells, including type II pneumocytes and lymphocytes (7). This would hence explain the severe pulmonary involvement, which is frequently observed in COVID-19, encompassing the development of interstitial pneumonia and occasional progression towards acute respiratory distress syndrome (ARDS) (8). COVID-19 patients may also progressively develop lymphopenia, seen especially in those with severe disease (9), which may be accompanied by immunosuppression, thus predisposing patients to severe co-infections by other microorganisms, especially bacteria (10). Nevertheless, all ACE2-expressing cells, belonging to a wide variety of different organs and tissues, should be considered a potential target for SARS$\mathrm{CoV}-2$. This supports the possibility of developing systemic disease, progressing towards multi organ failure (MOF) and death $(11,12)$.

One important aspect that has been recently highlighted, which may partially explain the heterogeneous development of signs and symptoms as well as the almost unpredictable clinical progression in infected individuals, is the possibility of intra-individual active recombination of SARS-CoV-2. This may lead to the generation several intra-host variants of the virus, characterized by various degrees of attenuated or magnified virulence (13). The presence of these biologically heterogeneous haplotypes of the virus, as well as their variable interplay with individual genetic and epigenetic characteristics, will make it difficult to predict the course of disease in a single individual. This may also partially explain the remarkable difference in the case fatality rate observed between countries, which would suggest either the possibility of natural selection of more virulent viral clusters in certain areas, or the more aggressive behavior of the virus in certain populations due to environmental, genetic or clinical factors (e.g., advanced age, major prevalence of co-morbidities, and so forth). Therefore, it will be challenging to develop a universal treatment for all COVID-19 patients, especially during the initial phase of the infection.

\section{High risk of inter-human transmission}

According to recent data, the basic reproduction number of SARS-CoV-2 (i.e., the R0) has been estimated at 2.4 (which means that each infected patient has the potential to infect 2.4 other healthy people), ranging between $\sim 2.2$ in China (14) and $\sim 2.8$ in Italy (15). This value seems globally comparable to that of SARS (i.e., 2.0-5.0) and MERS (i.e., 2.7-3.9) (16), and attest that SARS-CoV-2 infection is likely to have a rapid and sustained spread. In fact, it is generally assumed that the number of people infected is likely to increase whenever the $\mathrm{R} 0$ is higher than 1 , whilst the infection will progressively cease when R0 is lower than 1 . Biggerstaff $e t$ al. pooled data of 24 different studies, which portrayed 47 seasonal influenza epidemics (17), and concluded that the median R0 for seasonal influenza is 1.28 (interquartile range, 1.19-1.37), i.e., virtually half that of COVID-19.

\section{Long incubation time combined with early and sustained viral load}

Although the R0 of SARS-CoV-2 is similar to that of SARS and MERS, some additional specific features would explain the much-enhanced viral spread in the population. Several 
studies on the incubation period of SARS-CoV-2 that have been published thus far suggest that incubation may be estimated at $\sim 6.4$ days, with a 95 -percentile range between 2.1-11.1 days (18). This period is apparently comparable to that of MERS (i.e., between 4-7 days) and slightly longer than that of SARS (i.e., between 3-5 days). A recent study by Lauer et al. attempted to provide a reliable estimation of the number of symptomatic SARS-CoV-2 infections which may remain undiagnosed during active monitoring (19). It was alarmingly concluded that, under conservative assumptions, up to $1 \%$ of all COVID-19 cases may not develop symptoms even after 2 weeks of quarantine or active monitoring.

Therefore, the crucial question that follows is whether SARS-CoV-2 infected individuals would be capable of transmitting the infection during this relatively long incubation period. According to recent data published by Wang et al. (20), the virus can be found across a large number of specimens for a variable number of days. In particular, the rate of positive specimens was as high as $93 \%$ in bronchoalveolar lavage fluid, $72 \%$ in sputum, $63 \%$ in nasal swabs, $46 \%$ in fibrobronchoscope brush biopsy, $32 \%$ in pharyngeal swabs and 29\% in feces. Direct contact with each of these SARS-CoV-2 infected materials may carry a significant risk of contracting the infection. Notably, SARSCoV-2 viremia can be present in up to $15 \%$ of COVID-19 patients (21), which has many unfavorable implications with respect to blood donation.

Reliable evidence has been provided that SARS-CoV-2 may be present in the throat, and especially in the nose, a few days before symptoms onset. An interesting study by Zou et al. demonstrated that completely asymptomatic subjects may display viral loads similar to those of symptomatic patients, which supports the hypothesis of virus transmissibility by asymptomatic, or only mildly symptomatic, patients (22). These findings were confirmed by Woelfel et al. (23). These authors studied nine SARSCoV-2 positive patients displaying only mild upper respiratory tract symptoms, which may go undetected or under-diagnosed according to the current guidelines. Pharyngeal viral shedding was found to be very high in the first symptomatic days in these patients, with a viral load that was found to be several orders of magnitude higher than that of SARS. Seroconversion was found to occur 6-12 days after, but was not accompanied by complete cessation of viral shedding. This would hence provides further support to the high possibility of a pre- or oligosymptomatic transmission, with a risk that may be substantially higher than for SARS.

An adjunctive problem is limited viral infection of the upper respiratory tract tissue, where ACE2 receptors are minimally expressed. This is reflected in the low prevalence of typical upper respiratory tract symptoms such as sore throat and sneezing, which are only reported in a limited number of COVID-19 patients (i.e., below $20 \%$ ) (24). The lack of mild symptoms may delay the diagnosis of COVID-19 until appearance of more severe lower respiratory tract involvement.

\section{Presence of asymptomatic or mildly symptomatic subjects}

Beyond the real problem of SARS-COV-2 transmission during the incubation phase, the possibility of transmission by totally or mildly symptomatic COVID-19 cases must be considered. Although no definitive data are available on this matter, Mizumoto et al. carried out a straightforward analysis on all passengers of the Diamond Princess cruise ship (25), concluding that the asymptomatic proportion of COVID-19 cases in the population may be as high as $17.9 \%$ (95\% credible interval, 15.5-20.2\%). Slightly higher data have been reported by Nishiura et al., who studied Japanese citizens evacuated from Wuhan (26). These authors concluded that the number of asymptomatic patients can be as high as $30.8 \%$ (95\% confidence interval: $7.7-53.8 \%$ ). This would mean that between $1: 3$ and $1: 5$ patients with SARS-CoV-2 infection may not display suggestive symptoms and shall be potential carriers of infection.

\section{Healthcare challenges due to disease severity}

The recent summary report published by the Chinese Center for Disease Control and Prevention on 72,314 COVID-19 cases revealed that SARS-CoV-2 will not just cause significant morbidity and mortality, but will also irreversibly derange the organization of the healthcare system. Briefly, although the clinical spectrum of disease will probably remain mild in the vast majority of cases (i.e., around $80 \%$ ), up to $15 \%$ of patients may progress towards severe disease (i.e., needing at least ventilation support), whilst nearly $5 \%$ of all cases will develop critical illness, requiring intensive care (12). Again, hypothesizing a similar number of people infected as influenza, this would theoretically translate into nearly 208 million people needing mechanical ventilation support, and approximately 69 million people needing intensive care unit (ICU) admission, worldwide. Although 
we sincerely hope that these numbers will never be reached, it is now clear that even in the best case scenario based on effective infection control, COVID-19 has and will continue to impose a dramatic strain on many critical care facilities, even in countries or territories with adequate resources and personnel (15). As such, this outbreak cannot be considered now, or for foreseeable future, an "ordinary" emergency. No health care system, and no medical branch including laboratory medicine (27), is prepared to face this virtually unpredictable challenge.

\section{Environmental contamination}

A recent study published by Ong et al. confirmed that environmental contamination due to persistence of the virus within respiratory droplets and fecal material is possible (28). Viral load was found to be especially high in toilet bowls, sinks, and air exhaust systems. Although definitive data on viral stability are still unavailable, a preliminary investigation suggests that the half-life of SARS-CoV-2 may be $\sim 1.2$ hours in droplets ( $95 \%$ credible interval, 0.64 2.64 hours) (29). Even more importantly, viable virus could be detected for up to 3 hours in aerosol, for up to 24 hours on cardboard and for up to 72 hours on plastic and stainless steel, though the titer was considerably low at the end of the relative observation periods. Taken together, these finding would suggest that SARS-CoV-2 displays a relatively long stability period in the environment. This supports the recommendations to adopt strict and reinforced measures for promoting widespread hand and environmental hygiene.

\section{Viral shedding after symptom relief}

Last, but nonetheless important, is the possibility that the virus could be transmitted at the end of the infection, after symptoms have ceased. Instances of such cases have already been published (30,31). Further evidence has been provided that the RNA of SARS-CoV-2 could be detected in feces for several days after patient illness or during convalescence (32). Woelfel $\mathrm{et} \mathrm{al}$. provided clear evidence of prolonged viral shedding in sputum after cessation of symptoms (23). This strongly suggests that the risk of inter-personal transmission remains substantial even after termination of symptoms.

\section{What the future holds}

As we described, SARS-CoV-2 appears to be the wrong virus at the wrong time, such that it should be considered a "perfect storm" (Table 2). This virus, with its high interhuman possibility of transmission even from asymptomatic or mildly-symptomatic subjects, would have not caused a similar outbreak decades ago, when movement of people across the world was considerably lower. According to the statistics of the World Tourism Organization (UNWTO), global tourism has increased exponentially during the past 30 years, from 0.4 billion tourists in 1990 , to over 1.4 billion in 2018 (i.e., 3.5-fold increase) (33). It is undeniable that this enormous movement of people has dramatically contributed to foster the current epidemic. On the other hand, this same virus would probably not cause such a tragedy in future decades, when advancements in our understanding of viral biology and the availability of effective antiviral treatments are likely to be magnified.

Predicting how this pandemic disease will now evolve is virtually impossible, neither in a short- or mediumterm. There are still too many characteristics of this virus that we do not yet understand. Hopefully, over the next several weeks, our scientific knowledge will advance and new interventional possibilities will subsequently emerge. For the time being, however, we must consider the consequences of inaction. It is readily apparent, that if further action is not taken, the progression of outbreak in the general population will likely follow an exponential curve, that will then culminate in a global tragedy (15).

As the development and mass production of effective vaccines against SARS-CoV-2 will take time (i.e., between 1 and 2 years from now), and considering that clinical trials with some potentially effective antiviral agents (e.g., remdesivir, chloroquine), immunomodulatory and anti-inflammatory drugs (e.g., baricitinib, ruxolitinib, fedratinib) or anticancer agents such as aplidin (Plitidepsin, i.e., a drug for treatment of multiple myeloma approved in Australia), are still underway $(34,35)$, preventative controlling measures must be established. Human-to-human transmission of SARS-CoV-2 is through respiratory droplets, which are especially generated when an infected individual (even if asymptomatic) coughs or sneezes. Maintenance of an adequate inter-personal distance or use of facemask in symptomatic individuals may hence be effective to prevent droplets that may propagate from an infected patient to a healthy person.

While basic preventative and hygienic measures seem logical and straightforward, many, including policy makers, are still largely underestimating and overlooking the risks of this infection. Therefore, at this time, more aggressive measures need to be established, with last but not least, nationwide lockdowns, as established by China first, and then followed 
by Italy, Spain, France and an increasing number of other countries. Moreover, strict adherence to the recommendation that an inter-personal distance of at least 1 meter for people engaged in essential public services (healthcare, army, police, fire department and so forth) is required. Moreover, public allotment of a minimum level of exercise to prevent the adverse metabolic changes of physical inactivity should be encouraged (36). Finally, everyone should be inexcusably aware that this is not a drill and inadequate actions can result in tragic consequences; joining forces with science and medicine, and working together, is the only way to win this war.

\section{Acknowledgments}

Funding: None.

\section{Footnote}

Conflicts of Interest: All authors have completed the ICMJE uniform disclosure form (available at http://dx.doi. org/10.21037/atm.2020.03.157). GL serves as an unpaid Editor-in-Chief of Annals of Translational Medicine from Feb 2020 to Jan 2022. FSG serves as an unpaid editorial board member of Annals of Translational Medicine from Mar 2019 to Feb 2021. BMH has no conflicts of interest to declare.

Ethical Statement: The authors are accountable for all aspects of the work in ensuring that questions related to the accuracy or integrity of any part of the work are appropriately investigated and resolved.

Open Access Statement: This is an Open Access article distributed in accordance with the Creative Commons Attribution-NonCommercial-NoDerivs 4.0 International License (CC BY-NC-ND 4.0), which permits the noncommercial replication and distribution of the article with the strict proviso that no changes or edits are made and the original work is properly cited (including links to both the formal publication through the relevant DOI and the license). See: https://creativecommons.org/licenses/by-nc-nd/4.0/.

\section{References}

1. Mattiuzzi C, Lippi G. Which lessons shall we learn from the 2019 novel coronavirus outbreak? Ann Transl Med 2020;8:48.

2. Coronaviridae Study Group of the International Committee on Taxonomy of Viruses. The species Severe acute respiratory syndrome-related coronavirus: classifying 2019-nCoV and naming it SARS-CoV-2. Nat Microbiol 2020. [Epub ahead of print].

3. Mahase E. Covid-19: WHO declares pandemic because of "alarming levels" of spread, severity, and inaction. BMJ 2020;368:m1036.

4. World Health Organization. Coronavirus disease 2019 (COVID-19) Situation Report - 55. Available online: https://www.who.int/emergencies/diseases/novelcoronavirus-2019/situation-reports/. Last accessed, March 16, 2020.

5. Paget J, Spreeuwenberg P, Charu V, et al. Global mortality associated with seasonal influenza epidemics: New burden estimates and predictors from the GLaMOR Project. J Glob Health 2019;9:020421.

6. Lippi G, Plebani M. The novel coronavirus (2019-nCoV) outbreak: think the unthinkable and be prepared to face the challenge. Diagnosis (Berl) 2020. [Epub ahead of print].

7. Xu H, Zhong L, Deng J, et al. High expression of ACE2 receptor of 2019-nCoV on the epithelial cells of oral mucosa. Int J Oral Sci 2020;12:8.

8. Jin YH, Cai L, Cheng ZS, et al. A rapid advice guideline for the diagnosis and treatment of 2019 novel coronavirus (2019-nCoV) infected pneumonia (standard version). Mil Med Res 2020;7:4.

9. Lippi G, Plebani M. Laboratory abnormalities in patients with COVID-2019 infection. Clin Chem Lab Med 2020. [Epub ahead of print].

10. Lippi G, Plebani M. Procalcitonin in patients with severe coronavirus disease 2019 (COVID-19): a meta-analysis. Clin Chim Acta 2020. [Epub ahead of print].

11. Chen N, Zhou M, Dong X, et al. Epidemiological and clinical characteristics of 99 cases of 2019 novel coronavirus pneumonia in Wuhan, China: a descriptive study. Lancet 2020;395:507-13.

12. Wu Z, McGoogan JM. Characteristics of and Important Lessons From the Coronavirus Disease 2019 (COVID-19) Outbreak in China: Summary of a Report of 72314 Cases From the Chinese Center for Disease Control and Prevention. JAMA 2020. [Epub ahead of print].

13. Shen Z, Xiao Y, Kang L, et al. Genomic diversity of SARSCoV-2 in Coronavirus Disease 2019 patients. Clin Infect Dis 2020. [Epub ahead of print].

14. Li Q, Guan X, Wu P, et al. Early Transmission Dynamics in Wuhan, China, of Novel Coronavirus-Infected Pneumonia. N Engl J Med 2020. [Epub ahead of print]. 15. Remuzzi A, Remuzzi G. COVID-19 and Italy: what next? 
Lancet 2020. [Epub ahead of print].

16. Zhao S, Lin Q, Ran J, et al. Preliminary estimation of the basic reproduction number of novel coronavirus (2019$\mathrm{nCoV}$ ) in China, from 2019 to 2020: A data-driven analysis in the early phase of the outbreak. Int J Infect Dis 2020;92:214-7.

17. Biggerstaff M, Cauchemez S, Reed C, et al. Estimates of the reproduction number for seasonal, pandemic, and zoonotic influenza: a systematic review of the literature. BMC Infect Dis 2014 Sep 4;14:480.

18. Backer JA, Klinkenberg D, Wallinga J. Incubation period of 2019 novel coronavirus (2019-nCoV) infections among travellers from Wuhan, China, 20-28 January 2020. Euro Surveill 2020. doi: 10.2807/1560-7917. ES.2020.25.5.2000062.

19. Lauer SA, Grantz KH, Bi Q. et al. The Incubation Period of Coronavirus Disease 2019 (COVID-19) From Publicly Reported Confirmed Cases: Estimation and Application. Ann Intern Med 2020. [Epub ahead of print].

20. Wang W, Xu Y, Gao R, et al. Detection of SARS-CoV-2 in Different Types of Clinical Specimens. JAMA 2020. [Epub ahead of print].

21. Huang C, Wang Y, Li X, et al. Clinical features of patients infected with 2019 novel coronavirus in Wuhan, China. Lancet 2020;395:497-506.

22. Zou L, Ruan F, Huang M, et al. SARS-CoV-2 Viral Load in Upper Respiratory Specimens of Infected Patients. N Engl J Med 2020. doi: 10.1056/NEJMc2001737. [Epub ahead of print].

23. Woelfel R, Corman VM, Guggemos W, et al. Clinical presentation and virological assessment of hospitalized cases of coronavirus disease 2019 in a travelassociated transmission cluster. medRxiv 2020 doi: 10.1101/2020.03.05.20030502.

24. Sun P, Qie S, Liu Z, et al. Clinical characteristics of 50466 hospitalized patients with 2019-nCoV infection. J Med Virol 2020. [Epub ahead of print].

25. Mizumoto K, Kagaya K, Zarebski A, et al. Estimating the asymptomatic proportion of coronavirus disease 2019 (COVID-19) cases on board the Diamond Princess cruise ship, Yokohama, Japan, 2020. Eurosurveillance 2020;25:2000180.

26. Nishiura H, Kobayashi T, Miyama T, et al. Estimation of the asymptomatic ratio of novel coronavirus infections
(COVID-19). Int J Infect Dis 2020. [Epub ahead of print].

27. Lippi G, Plebani M. The critical role of laboratory medicine during coronavirus disease 2019 (COVID-19) and other viral outbreaks. Clin Chem Lab Med 2020. [Epub ahead of print].

28. Ong SWX, Tan YK, Chia PY, et al. Air, Surface Environmental, and Personal Protective Equipment Contamination by Severe Acute Respiratory Syndrome Coronavirus 2 (SARS-CoV-2) From a Symptomatic Patient. JAMA 2020. [Epub ahead of print].

29. van Doremalen N, Bushmaker T, Morris DH, et al. Aerosol and Surface Stability of SARS-CoV-2 as Compared with SARS-CoV-1. N Engl J Med 2020. [Epub ahead of print].

30. Chen D, Xu W, Lei Z, et al. Recurrence of positive SARSCoV-2 RNA in COVID-19: A case report. Int J Infect Dis 2020. [Epub ahead of print].

31. Ruan ZR, Gong P, Han W, et al. A case of 2019 novel coronavirus infected pneumonia with twice negative 2019nCoV nucleic acid testing within 8 days. Chin Med J (Engl) 2020. [Epub ahead of print].

32. Han H, Luo Q, Mo F, et al. SARS-CoV-2 RNA more readily detected in induced sputum than in throat swabs of convalescent COVID-19 patients. Lancet Infect Dis 2020. [Epub ahead of print].

33. World Tourism Organization. World Tourism Organization data. Available online: https://www.unwto. org/. Last accessed, March 15, 2020.

34. Dong L, Hu S, Gao J. Discovering drugs to treat coronavirus disease 2019 (COVID-19). Drug Discov Ther 2020;14:58-60.

35. Stebbing J, Phelan A, Griffin I, et al. COVID-19: combining antiviral and anti-inflammatory treatments. Lancet Infect Dis 2020. [Epub ahead of print].

36. Lippi G, Henry MB, Sanchis-Gomar F. Physical inactivity and cardiovascular disease at the time of coronavirus disease 2019 (COVID-19). Eur J Prev Cardiol 2020. [Epub ahead of print].

Cite this article as: Lippi G, Sanchis-Gomar F, Henry BM. Coronavirus disease 2019 (COVID-19): the portrait of a perfect storm. Ann Transl Med 2020;8(7):497. doi: 10.21037/ atm.2020.03.157 